\title{
Aberrant promoter methylation of the $C D 4$ gene in peripheral blood cells of mastitic dairy cows
}

\author{
X.S. Wang ${ }^{1}$, Y. Zhang ${ }^{1}$, Y.H. He ${ }^{1}$, P.P. Ma ${ }^{1}$, L.J. Fan ${ }^{1}$, Y.C. Wang ${ }^{1}$, \\ Y.I. Zhang ${ }^{1}$, D.X. Sun ${ }^{1}$, S.L. Zhang', C.D. Wang', J.Z. Song ${ }^{2}$ and Y. Yu ${ }^{1}$ \\ ${ }^{1}$ Key Laboratory of Agricultural Animal Genetics and Breeding, \\ National Engineering Laboratory for Animal Breeding, \\ College of Animal Sciences and Technology, \\ China Agricultural University, Beijing, China \\ ${ }^{2}$ Department of Animal \& Avian Sciences, \\ University of Maryland, College Park, MD, USA \\ Corresponding author: Y. Yu \\ E-mail: yuying@cau.edu.cn
}

Genet. Mol. Res. 12 (4): 6228-6239 (2013)

Received December 5, 2012

Accepted March 27, 2013

Published December 4, 2013

DOI http://dx.doi.org/10.4238/2013.December.4.10

\begin{abstract}
Bovine mastitis is the most common and costly disease of dairy cattle. Cluster of differentiation 4 (CD4) is closely related to the immune response in mastitis. We quantified promoter $\mathrm{CpG}$ methylation levels of the $C D 4$ gene in Chinese Holsteins with clinical mastitis (CM) and in healthy controls; these levels were quantitatively detected with bisulfite pyrosequencing assays and confirmed by cloning sequencing. We found that the bovine $C D 4$ promoter had 16\% more methyl groups in the cows with $\mathrm{CM}(75.0 \pm 5.8 \%)$ compared to the controls $(59.0 \pm 8.5 \%)$. The decreased expression level of $C D 4$ in CM cows may be downregulated by the increased DNA methylation levels in the CD4 promoter. Two-dimensional hierarchical clustering analyses showed large differences in promoter CD4 methylation between mastitic and healthy cows; the dendrogram clearly distinguished the cows with clinical mastitis from healthy controls based on methylation levels. The DNA methylation level of the CD4 gene was strongly influenced by mastitis status in all comparisons. We suggest that
\end{abstract}


the DNA methylation level of the $C D 4$ promoter can be used as a molecular marker for clinical mastitis in dairy cows.

Key words: $C D 4$; Promoter DNA methylation; Cow; Clinical mastitis; Peripheral blood cell

\section{INTRODUCTION}

Mastitis is a common disease in dairy cows. Either clinical or subclinical mastitis has been detected in about one-third to two-thirds of lactating cows all over the world (Ma et al., 2010; NMC, 2011). After cows are infected with pathogens, the number of somatic cells in the mammary gland increases rapidly. The somatic cells mainly migrate from blood and primarily include lymphocytes, neutrophils and macrophages (Halasa et al., 2009). Previous studies have suggested that cows with somatic cell counts (SCC) of less than $1 \times 10^{5}$ cells per milliliter milk are not likely to be infected with major mastitis pathogens, while cows with SCC greater than $5 \times 10^{5}$ are probably infected (Halasa et al., 2009). However, SCC is an inflammatory endpoint and varies over lactations and stages of lactation as well as various environmental factors. Thus stable molecular marker for selection against mastitis in dairy cattle is needed.

DNA methylation is one of the key epigenetic modifications (Weber et al., 2007), which stably decreases gene expression and plays a crucial role in inflammatory diseases (Vanselow et al., 2006). The potential prognostic value of promoter hypermethylation of the as 1-casein gene has been shown in mammary gland tissue of dairy cows for acute mastitis (Vanselow et al., 2006). More recently, the use of locus-specific methylation patterns of peripheral blood cells has been suggested as a useful biomarker in breast cancer (Widschwendter et al., 2008; Choi et al., 2009) and inflammatory diseases (Wilson, 2008; Backdahl et al., 2009).

Cluster of differentiation 4 (CD4), a key leukocyte surface marker expressed on the surface of $\mathrm{CD}^{+}$lymphocytes, is a critical molecular mediator influencing antibacterial responses (Rivas et al., 2007; Zhou, 2007). A previous study reported that compared with uninfected cows, cows infected with Staphylococcus aureus had lower proportions of $\mathrm{CD}^{+} \mathrm{T}$ cells in peripheral blood (Rivas et al., 2007). It has been proposed that epigenetic silencing of the $C D 4$ gene by DNA methylation affects the development and differentiation of $\mathrm{CD}^{+} \mathrm{T}$ cells in the inflammatory response (Landolfi et al., 1997; Ellmeier et al., 1999; Zou et al., 2001; Wei et al., 2009). In a recently published study, we disclosed that the promoter region of avian CD4 gene was demethylated after Marek's disease virus infection in a line of chickens susceptible to Marek's disease, and that the down-methylation level was negatively correlated with the upregulation of $C D 4$ gene expression in the spleen tissue of chickens (Luo et al., 2011). However, the DNA methylation pattern of the bovine $C D 4$ gene and its relationship with mastitis status is still unclear.

In the present study, the promoter DNA methylation levels of bovine CD4 in whole blood were quantitatively measured in clinical mastitis and healthy cows of Chinese Holsteins. The mRNA expression level of CD4 in the cows was also checked and the relationship between methylation pattern with mastitis status and resistance in dairy cows was analyzed and discussed. 


\section{MATERIAL AND METHODS}

\section{Experimental animals}

Ninety-seven Chinese Holstein cows were randomly collected from four dairy farms in Beijing, China. They were of different parities ranging from one to five. All clinical mastitis $(\mathrm{CM})$ cows $(\mathrm{N}=46)$ were diagnosed by a trained veterinarian according to clinical symptoms including visible red swelling and inflamed mammary gland, as well as high SCC in milk (3.8 $\left.\pm 2.2 \times 10^{6} / \mathrm{mL}\right)$. Healthy controls $(\mathrm{N}=51)$, free of any current diagnoses relative to clinical mastitis, showed normal mammary gland and SCC $\left(4.7 \pm 3.6 \times 10^{4} / \mathrm{mL}\right)$. The milk samples were collected for SCC detection which was carried out by the official Dairy Center of China (Beijing, China), and the blood samples were collected aseptically from the jugular vein of cows by a professional veterinarian.

\section{DNA extraction and bisulfite treatment}

Cow genomic DNA was extracted from peripheral blood cells for each sample using the DP-318 Blood DNA kit (TianGen Biotech Co., Ltd, China). DNA concentration was measured with the NanoDropTM ND-2000c Spectrophotometer (Thermo Scientific, Inc., USA). Sodium bisulfite conversion of $1 \mu \mathrm{g}$ genomic DNA for each sample was conducted using the EZ DNA Methylation Golden kit according to manufacturer instructions (ZYMO Research, Irvine, CA, USA). Bisulfite-converted DNA was eluted in $20 \mu \mathrm{L}$ elution buffer (ZYMO Research).

\section{Primers and hot start PCR}

PCR primers and sequencing primers of the CD4 gene (NCBI accession No. NM_001103225) used for DNA methylation assay were designed with PSQ Assay Design software (Qiagen, GmBH, Germany) and Oligo 6.0 software (Table 1). Biotin-labeled universal primer (5'- GGG ACA CCG CTG ATC GTT TA-3') was used in the study as described in our previous work (Yu et al., 2008a; Yu et al., 2008b).

Table 1. Primers information for pyrosequencing assay and real-time RT-PCR.

\begin{tabular}{lll}
\hline Gene & Primer & Sequence $^{A}$ \\
\hline CD4-methylation & Forward & 5'-GTTGGGGGGAAGAGGGTATAG-3' \\
& Reverse & 5'-GGGACACCGCTGATCGTTTAAAATCCCTTCAAAAAACCATATCTC -3' \\
& Sequencing & 5'-TTTATAGGTATTTTTATTTT-3' \\
& Assay & 5'-TTTYGTAYGGTTTTATTAGTTTTTTTAGTTYGTYGGYGGAT-3' \\
CD4-Real time & Forward & 5'-AGCAGAAAGTGAAACTCGTGG-3' \\
& Reverse & 5'-ACCAACTTCGGCTGATTTGAG-3' \\
GAPDH-Real time & Forward & 5'-CCCTGAGACAAGATGGTGAAG-3' \\
& Reverse & 5'-CATGTAGTGAAGGTCAATGAAG-3' \\
\hline
\end{tabular}

${ }^{\mathrm{A}} \mathrm{Y}$ stands for $\mathrm{C} / \mathrm{T}$. Bold $\mathrm{Y}$ is the $\mathrm{CpG}$ sites assayed in bovine $C D 4$ promoter.

The hot start PCR was carried out in $25 \mu \mathrm{L}$ solution including 15 to 20 ng bisulfitetreated DNA, $12.5 \mu \mathrm{L}$ Hot start PCR premix (ZYMO Research), $0.5 \mu \mathrm{M}$ forward primer, $0.05 \mu \mathrm{M}$ reverse primer with universal tail and $0.45 \mu \mathrm{M}$ biotin-labeled universal primer. PCR cycling conditions were $95^{\circ} \mathrm{C}$ for $10 \mathrm{~min}$, followed by 50 cycles of $94^{\circ} \mathrm{C}$ for $30 \mathrm{~s}, 50$ to $60^{\circ} \mathrm{C}$ 
for $45 \mathrm{~s}$, and $72^{\circ} \mathrm{C}$ for $45 \mathrm{~s}$, and a final incubation at $72^{\circ} \mathrm{C}$ for $10 \mathrm{~min}$. The PCR products were checked using $2 \%$ agarose gels with ethidium bromide.

\section{Quantitative DNA methylation analyses by pyrosequencing and cloning sequencing}

To quantitatively analyze the promoter methylation level of $C D 4$ gene in the cows with $\mathrm{CM}$ and healthy controls, pyrosequencing assays were conducted and confirmed by cloning sequencing. DNA methylation level was tested for the five $\mathrm{CpG}$ sites located in the promoter region of bovine CD4 (USCS database: Bau4.0, Chr5: 10637520 10637027) (Figure 1A, black box).

Promoter DNA methylation analyses were conducted using pyrosequencing techniques on a Pyro Q-CpG system (Qiagen) according to manufacturer protocol. Based on the concentration of the PCR products, 10 to $25 \mu \mathrm{L}$ bisulfite PCR products were used for pyrosequencing reactions (Yu et al., 2008a,b). In brief, the PCR products were bound to Streptavidin Sepharose High Performance (GE Healthycare). The Sepharose beads containing the biotin-labeled PCR products were purified in $70 \%$ ethanol for $30 \mathrm{~s}$, denatured in denature buffer $(0.2 \mathrm{M} \mathrm{NaOH})$ for $30 \mathrm{~s}$, and washed with washing buffer for $45 \mathrm{~s}$ using the Pyrosequencing Vacuum Prep Tool (Qiagen). Next, $0.5 \mu \mathrm{M}$ pyrosequencing primer was annealed to the purified single-stranded PCR product with annealing buffer (Qiagen). The levels of promoter $\mathrm{CpG}$ methylation were expressed as the percentage $\mathrm{mC} /(\mathrm{mC}+\mathrm{C})$, in which, $\mathrm{mC}$ denotes methylated cytosine and $\mathrm{C}$ means unmethylated cytosine at each $\mathrm{CpG}$ site. Non$\mathrm{CpG}$ cytosine residues were used as internal controls to verify bisulfite conversion. The PCR products were cloned into pGM-T vector using a TOPO-clone kit according to manufacturer instructions, and then sequenced using an ABI 3730XL automated sequencer. At least 10 clones were sequenced for each individual.

\section{Real-time RT-PCR}

Total RNA was extracted from peripheral blood cells using the Trizol kit (Invitrogen, Carlsbad, CA, USA). Contaminated DNA was treated with DNAse (Qiagen). The first strand cDNA was synthesized from total RNA (500 ng per sample) using SuperScriptTM III Reverse Transcriptase (Invitrogen). Samples were then analyzed by real-time RT-PCR using the LightCyCler480 PCR system (Roche, Switzerland). The real time RT-PCR reactions were performed in $15 \mu \mathrm{L}$ solution with a LightCyCler480 SYBR Green I Master (Roche) according to manufacturer instructions. Two replicates were run for each reaction. The mRNA expression level of the CD4 gene was normalized to the housekeeping gene GAPDH (glyceraldehyde3phosphate dehydrogenase) in the corresponding samples. The PCR reactions were cycled 40 times after initial denaturation $\left(95^{\circ} \mathrm{C}, 5 \mathrm{~min}\right)$ with the following parameters: denaturation at $95^{\circ} \mathrm{C}$ for $15 \mathrm{~s}$, annealing at $60^{\circ} \mathrm{C}$ for $15 \mathrm{~s}$, and extension at $72^{\circ} \mathrm{C}$ for $35 \mathrm{~s}$ (the primers are shown in Table 1).

\section{Statistical analysis}

The difference in DNA methylation levels of each CpG site between CM cows and healthy controls was compared by the Student $t$-test. The quantitative methylation level of each $\mathrm{CpG}$ site for each sample was combined in a data matrix, which was used in a two- 
dimensional hierarchical clustering analysis with the $\mathrm{R}$ package for statistical analysis ( $\mathrm{Yu}$ et al., 2008a; Fuchikami et al., 2011). Relative quantification of gene expression level was performed by a $2^{(-\Delta \Delta \mathrm{Ct})}$ method. We also did regression analysis of DNA methylation level of CD4 promoter versus mRNA expression level of the gene in the whole blood cells of six cows ( 3 mastitic cows and 3 controls).

The effects of mastitis status on DNA methylation level of the $C D 4$ gene were analyzed using the general linear model (GLM) procedure of the SAS program (version 9.1.3). below.

Equation 1 was used to analyze the data pooled over four Holstein herds, as shown

$$
y_{i j l k}=\mu+p_{i}+h_{j} \times m_{l}+b s_{k}+e_{i j l k}
$$

Equation 2 was used to analyze the data from the largest herd, as shown below.

$$
y_{i j l k}=\mu+p_{i}+m_{l}+b s_{k}+e_{i j l k}
$$

$y_{i j J k}$ represents the DNA methylation level of the $k$ th cow with $i$ th parity and $j$ th herd in model 1 , and $y_{i l k}$ represents the DNA methylation level of the $k$ th cow with $i$ th parity in model $2 ; \mu$ is overall mean; $p_{i}$ is fixed effect of the ith parity $(i=1,2, \ldots, 5) ; h_{j} \times m_{l}$ is the combined effect of herd $\left(h_{j}, j=1,2,3\right.$ and 4 representing four herds) and healthy status $\left(m_{l}, 1=0\right.$ or 1 representing mastitis or controls, respectively); $s_{k}$ is random SCS effect of the $k$ th cow $(k=1$, $2, \ldots, 97$ in model $1, k=1,2, \ldots, 52$ in model 2$) ; b$ is the regression coefficient; $e_{i j l k}$ and $e_{i l k}$ are the random error in model 1 and model 2 , respectively.

\section{RESULTS}

\section{DNA methylation levels of the CpG sites in CD4 promoter}

To quantitatively analyze the promoter methylation level of the $C D 4$ gene in cows with $\mathrm{CM}$ and healthy controls, the typical methylation pyrograms are shown in Figure 1B and Figure $1 \mathrm{C}$ for the cows with $\mathrm{CM}$ and healthy controls, respectively. As shown in Table 2, the methylation rate of each of the five $\mathrm{CpG}$ sites in the cows with $\mathrm{CM}$ were very significantly higher (mean $\pm \mathrm{SE}=75.0 \pm 5.8 \%$ ) than that in the healthy cattle (mean $\pm \mathrm{SE}=59.0 \pm 8.5 \%)(\mathrm{P}$ $<0.01$ ). The pyrosequencing results were further validated by bisulfite and cloning sequencing methods as shown in Figure 1D and Figure 1E.

\section{DNA methylation pattern of each CpG site}

Two-way hierarchical clustering analysis of methylation levels of the five $\mathrm{CpG}$ sites was conducted to classify samples and $\mathrm{CpG}$ sites into clusters according to their similarity. The DNA methylation profiles of all samples were shown in heat map format (Figure 2A). Dendrograms were used to visualize the clustering results. According to the left branch of the dendrograms, we could distinguish between mastitic cows ( $\mathrm{N}=46$, upper panel with red bar) and healthy controls $(\mathrm{N}=51$, lower panel with blue bar) in concordance with classification based on clinical diagnosis. The results indicated that the DNA methylation pattern could be an epigenetic marker for indication of clinical mastitic and healthy dairy cows. 
A 10598035

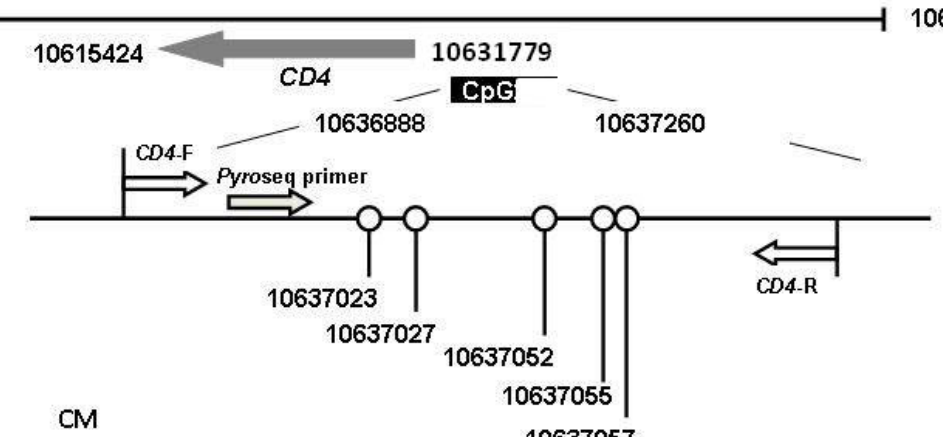

B

\section{F: ITIYGTAYGGITITATIAGITITITIAGTTYGTYGYGGAT}

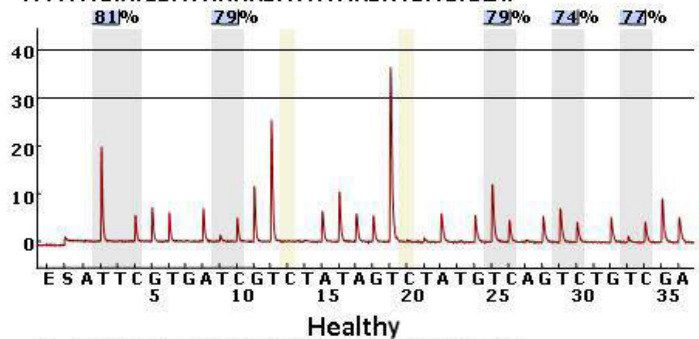

C

C6: TTYGTAYGGITITATIAGITIIITAGTYYGMGYGGAT

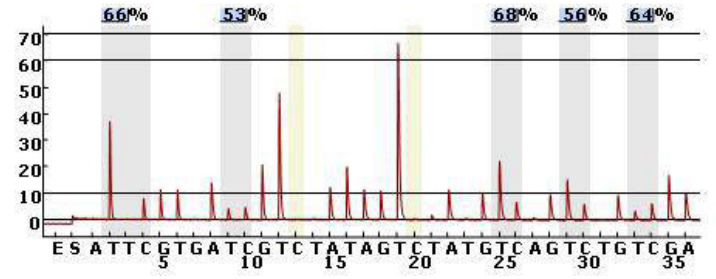

10637057

D

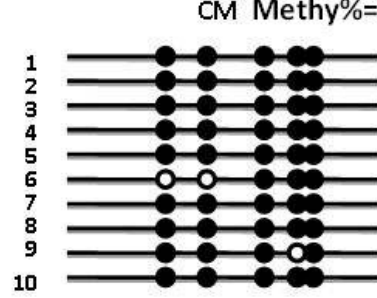

$\mathrm{E}$

Healthy Methy $\%=56 \%$

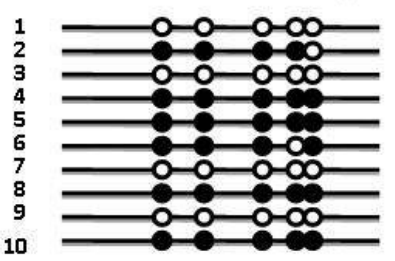

Figure 1. Results of bisulfite pyrosequencing and cloning sequencing for bovine $C D 4$ promoter. A. CpG sites and locations on the promoter region of bovine CD4 (black box, UCSC Genome Browser, bos Tau4). B. and C. Pyrosequencing profiles of CD4 DNA methylation in peripheral blood cells in CM and healthy cows, respectively. The percentage on each $\mathrm{CpG}$ site is the methylation percentage of ${ }^{\mathrm{m}} \mathrm{C} /\left({ }^{\mathrm{m}} \mathrm{C}+\mathrm{C}\right)$ on this site, in which ${ }^{\mathrm{m}} \mathrm{C}$ means methylated cytosine and $\mathrm{C}$ means unmethylated cytosine. D. and E. Bisulfite cloning sequencing results of CM and healthy cows, respectively. Ten clones of PCR products from bisulfite treated DNA were sequenced. Filled and open circles represent methylation and unmethylation $\mathrm{CpG}$ sites, respectively.

Table 2. Student $t$-test results of DNA methylation levels of $C D 4$ promoter between the clinical mastitis and healthy cows.

\begin{tabular}{lcccrr}
\hline \multirow{2}{*}{ Cows } & \multicolumn{4}{c}{ Methylation levels of the five CpG sites (means \pm SD, \%) } \\
\cline { 2 - 6 } & CpG1 & CpG2 & CpG3 & CpG4 & CpG5 \\
\hline Clinical mastitis $(\mathrm{N}=46)$ & $80.00 \pm 7.64$ & $72.59 \pm 8.14$ & $79.98 \pm 7.57$ & $68.98 \pm 9.5$ & $73.29 \pm 5.59$ \\
Healthy control $(\mathrm{N}=51)$ & $64.68 \pm 9.61$ & $50.08 \pm 12.8$ & $69.50 \pm 11.38$ & $50.50 \pm 8.8$ & $60.75 \pm 8.47$ \\
$\mathrm{P}$ & $1.28 \times 10^{-13}$ & $1.28 \times 10^{-17}$ & $4.32 \times 10^{-7}$ & $5.17 \times 10^{-17}$ & $5.26 \times 10^{-14}$ \\
\hline
\end{tabular}

\section{Relationship of transcriptional expression level of CD4 with DNA methylation level}

To assess the relationship between promoter DNA methylation status and transcriptional level of the $C D 4$ gene, we further examined the mRNA expression level of the gene in 
peripheral blood cells via real-time RT-PCR. The results showed that mRNA expression level of the gene was significantly lower in the cows with $\mathrm{CM}$ compared to the healthy controls $(\mathrm{P}<$ 0.05 , Figure $2 \mathrm{~B}$ ), which negatively correlated with the promoter methylation level of the $C D 4$ gene in the cows $\left(\mathrm{R}^{2}=0.4238\right.$, Figure $\left.2 \mathrm{C}\right)$.

To determine the possible reason why increased DNA methylation may repress a gene's expression, the binding sites of transcription factors (TFs) were predicted by TFSEARCH software (Heinemeyer et al., 1998). As shown in Figure 3, the first CpG site is located at the binding site of ADR1 activator and the fifth $\mathrm{CpG}$ site is within the binding site of the activators GATA-1 and GATA-2. The results suggested that the increased binding of methyl groups (CH3) at the $\mathrm{CpG}$ sites of $C D 4$ promoter may block the binding of the active TFs.
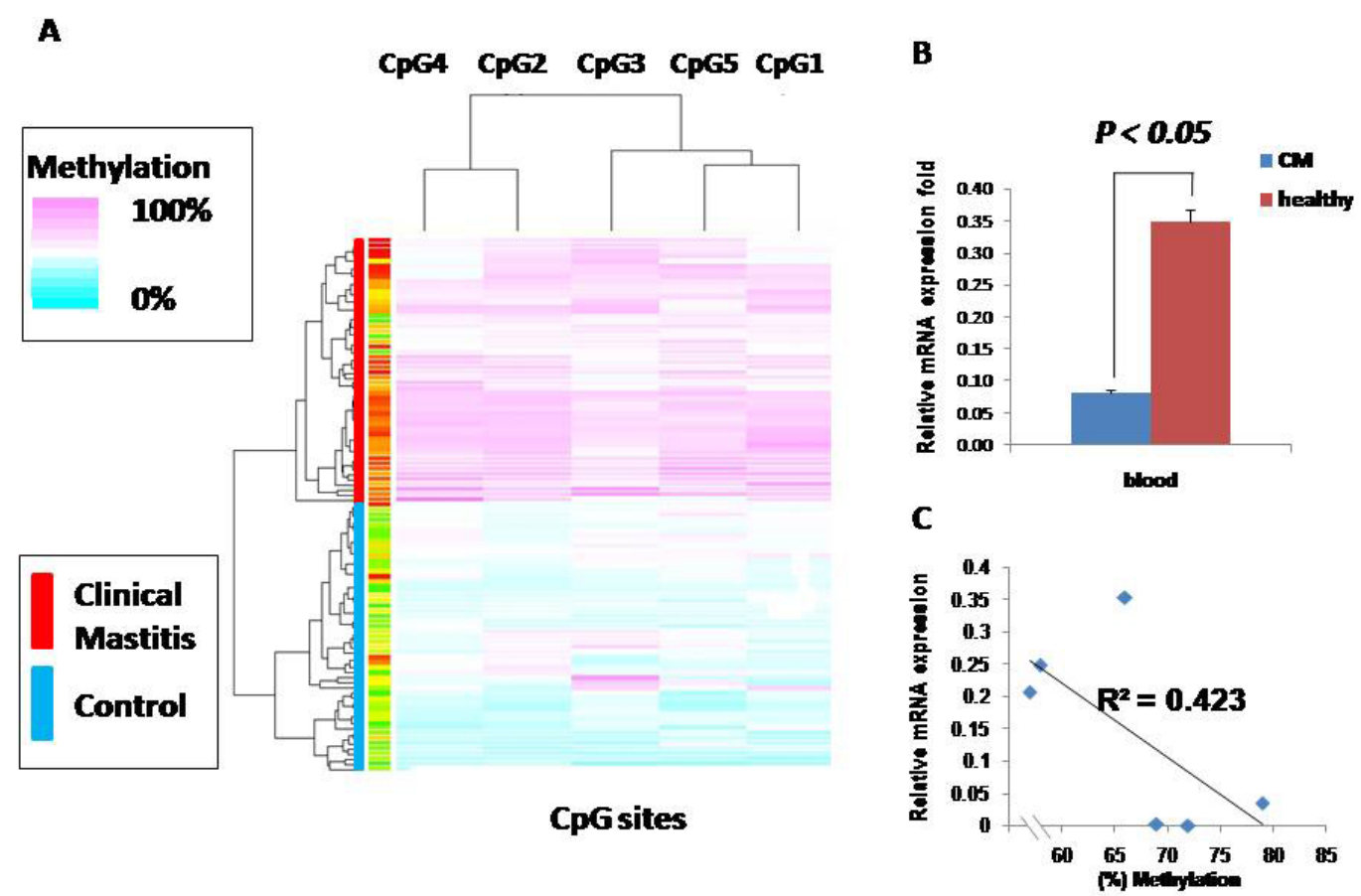

Figure 2. DNA methylation profile of bovine $C D 4$ gene and its relationship with gene expression levels in $\mathrm{CM}$ and control Holsteins. A. Two-way hierarchic cluster analysis of 97 samples (rows) and $5 \mathrm{CpG}$ sites at the promoter of $C D 4$ gene (columns). DNA methylation levels are depicted by a pseudocolor scale as indicated from pink (100\% methylated) to blue (nonmethylated). The upper branch of the dendrograms shows the similarity among the methylation levels of the five $\mathrm{CpG}$ sites. The left branch notes the similarity among $46 \mathrm{CM}$ cows and 51 healthy controls. B. mRNA expression results of $C D 4$ between clinical mastitis and healthy samples with real-time RTPCR. $\mathrm{N}=16$ for $\mathrm{CM}$ cows, $\mathrm{N}=13$ for healthy cows. C. Regression analysis of mRNA expression level of CD4 and DNA methylation contents of $C D 4$ promoter.

\section{Effect of the mastitis on DNA methylation level of CD4}

The effect of mastitis status on DNA methylation level of bovine CD4 gene was tested using two linear models. As shown in Table 3, the combined effect of herd and mastitis status had a highly significant effect on the DNA methylation level in all samples in the four herds (P 
$=0.0004$, model 1). Furthermore, in the largest herd, mastitis status had a significant effect on DNA methylation level of the gene $(\mathrm{P}=0.0136$, model 2$)$. However, different parities and SCS had no significant effect on DNA methylation level. The results showed that mastitis could cause high methylation level of $C D 4$ in lactating cows.

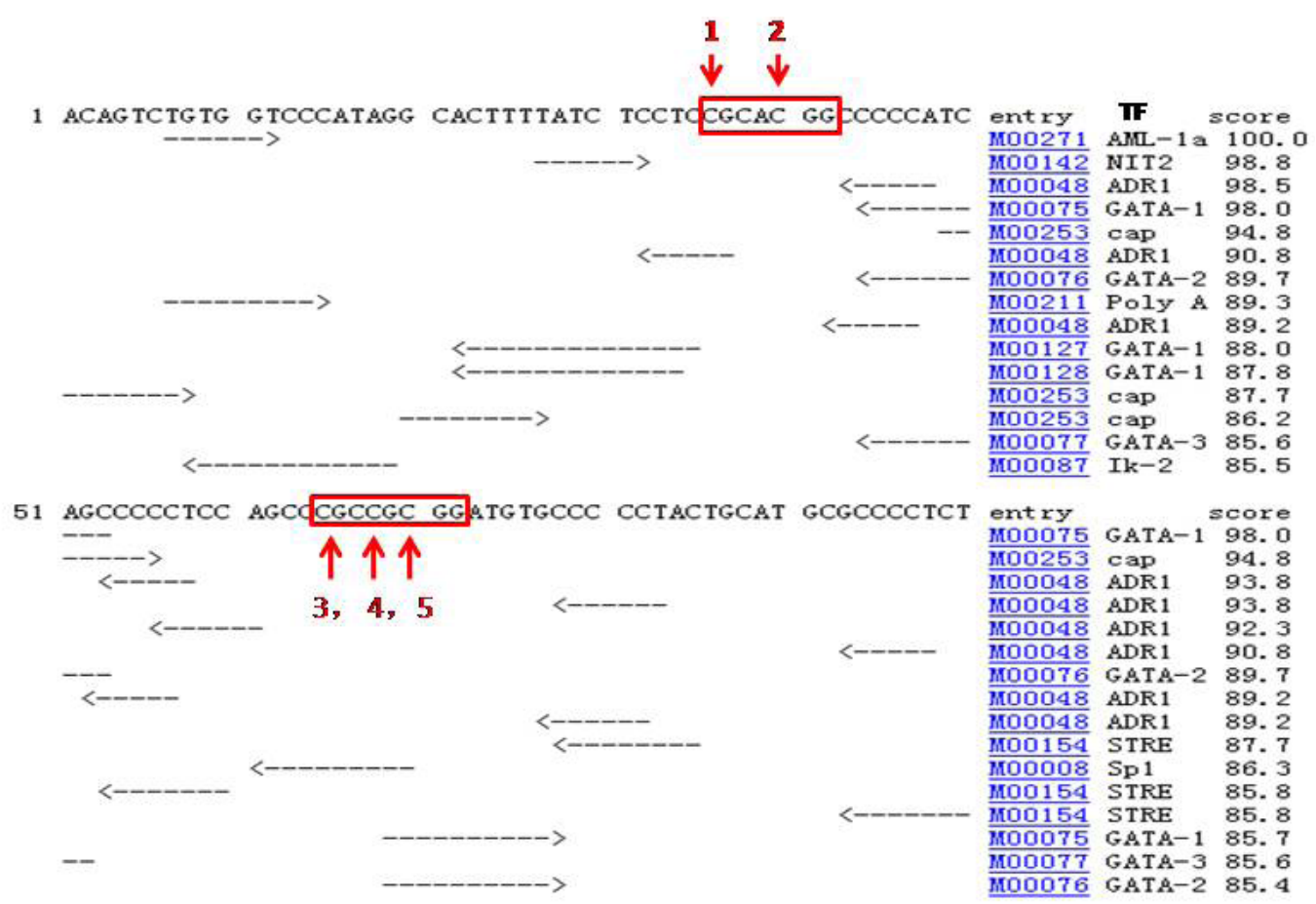

Figure 3. Predicted binding sites of transcription factors on the promoter region of $C D 4$ gene. Red arrows point the five $\mathrm{CpG}$ sites in the studied region. $\mathrm{TF}=$ predicted transcriptional factor.

\begin{tabular}{|c|c|c|c|c|c|}
\hline & $\mathrm{N}$ & Herd $\mathrm{x}$ Mastitis & Mastitis status & Parity & SCS \\
\hline Model 1 & 97 & $0.0004 * *$ & - & 0.5513 & 0.6012 \\
\hline Model 2 & 52 & - & $0.0136^{*}$ & 0.8126 & 0.9732 \\
\hline
\end{tabular}

$* * \mathrm{P}<0.01 ; * \mathrm{P}<0.05 ;(-)=$ not available. $\mathrm{SCS}=$ somatic cell score.

\section{DISCUSSION}

In the present study we quantitatively examined promoter methylation status and mRNA expression levels of bovine $C D 4$ gene in peripheral blood cells of Chinese Holsteins. According to the DNA methylation patterns of the five $\mathrm{CpG}$ sites of $C D 4$ promoter, we were able to distinguish the $\mathrm{CM}$ cows from the healthy controls. To the best of our knowledge, this is the first study disclosing the remarkable difference in DNA methylation pattern of $C D 4$ between $\mathrm{CM}$ and healthy dairy cows. 
As we know, SCC in milk of cows is an indicator of udder health status and is one of the most frequently performed tests to resist mastitis and improve milk quality worldwide. SCC are normally significantly increased in the milk of mastitic cows compared to healthy cows, which was also reflected in our study, where the SCC of the cows with CM was 85 times higher than that of the cows free of CM. However, conventional breeding selection methods based on log-transformed SCC have been proven inefficient in lowering the morbidity of mastitis in lactating cows, which is probably due to three possible reasons: (I) the heritability of SCC is low ( $h^{2}=0.092 \sim 0.187$ ) (Miglior et al., 2009); (II) SCC fluctuates over different lactations and stages of lactation as well as herds (de Haas et al., 2002); and (III) SCC is an inflammatory endpoint of mastitis and not a good marker for early diagnosis or selection against mastitis. Thus, a highly stable molecular marker of mastitis resistance is needed in dairy cattle (Burton and Erskine, 2003). The linage development and termination of T helper cells may be directed by CD4 protein in peripheral blood and spleen tissues (Zou et al., 2001; Luo et al., 2011). Most importantly, CD4 protein and $\mathrm{CD}^{+} \mathrm{T}$ cells play key roles in host resistance during the development of mastitis (Burton and Erskine, 2003; Rivas et al., 2007). DNA methylation serves as a stable molecular marker for gene silencing memory in mammals (Vanselow et al., 2006; Feil and Fraga, 2012), and previous studies have found that the transcriptional level of $C D 4$ regulated by DNA methylation in blood is directly related to T cell development (Landolfi et al., 1997; Zou et al., 2001). Our results showed that the cows with $\mathrm{CM}$ had distinctly increased DNA methylation level in CD4 promoter but downregulated expression of the gene in the peripheral blood cells of Chinese Holstein cows, while healthy cows showed the opposite. The negative correlation of DNA methylation and CD4 expression was consistent with the significant decrease in $\mathrm{CD}^{+} \mathrm{T}$ cells observed in the cows with mastitis (Rivas et al., 2001; Rivas et al., 2007). Thus DNA methylation level of CD4 promoter could be a helpful molecular marker for selection against mastitis in dairy cattle.

To date, comparison of the divergence of DNA methylation in whole blood between cases and controls of common diseases has been well documented (Nadeau et al., 2010; Chowdhury et al., 2011; Toperoff et al., 2011; Lin et al., 2012). However, whole blood consists of many functionally and developmentally distinct cell populations in varying proportions. Therefore, whole blood DNA methylation variation of genes should be performed with great caution (Reinius et al., 2012). Any methylation differences resulting from varying proportions of white blood cell types should be considered (Reinius et al., 2012). Our study revealed that mastitis could cause increased DNA methylation level of CD4 in lactating cows. To further elucidate the mastitis-contributing epigenetic mechanisms, an essential step is to isolate and measure DNA methylation level of $C D 4$ promoter region directly on $\mathrm{CD}^{+}$white blood cells, including $\mathrm{T}$ helper cells, monocytes, macrophages, and dendritic cells. We isolated the CD4 ${ }^{+}$ white blood cells from the peripheral blood of mastitic and control cows by flow cytometry (Figure 4). The results revealed that the proportion of $\mathrm{CD} 4^{+}$white blood cells was significantly lower in the CM cows $(25.90 \pm 10.12 \%, \mathrm{~N}=12)$ compared to the healthy ones $(35.50 \pm 6.42$ $\%, \mathrm{~N}=9)(\mathrm{P}<0.05)$. To understand the DNA methylation-mediated regulation of $C D 4$ expression on T lymphocytes, we performed an in-depth study of the DNA methylation status and expression levels of the $C D 4$ gene in $\mathrm{CD}^{+}{ }^{+}$white blood cells of Holstein cows.

Earlier studies have revealed that promoter hypermethylation suppresses gene expression, since up-methylated $\mathrm{CpG}$ sites may block the combination of active transcription factors (TFs) at the binding site (Li et al., 2010; Wang et al., 2010). Using the TFSEARCH 
software, three active TFs (ADR1, GATA-1 and GATA-2) were predicted to be located at the $\mathrm{CpG}$ sites of the bovine CD4 promoter. The three TFs were required for the activation of gene transcription combined with other factors (Fujiwara et al., 2004). The increased methyl group (CH3) binding at the $\mathrm{CpG}$ sites of the $\mathrm{CD} 4$ promoter implied that it may be involved in the on/ off switching of $C D 4$ gene expression. Therefore, a functional study requires the identification and characterization of the TFs that recruit chromatin modifying enzymes to these binding sites.
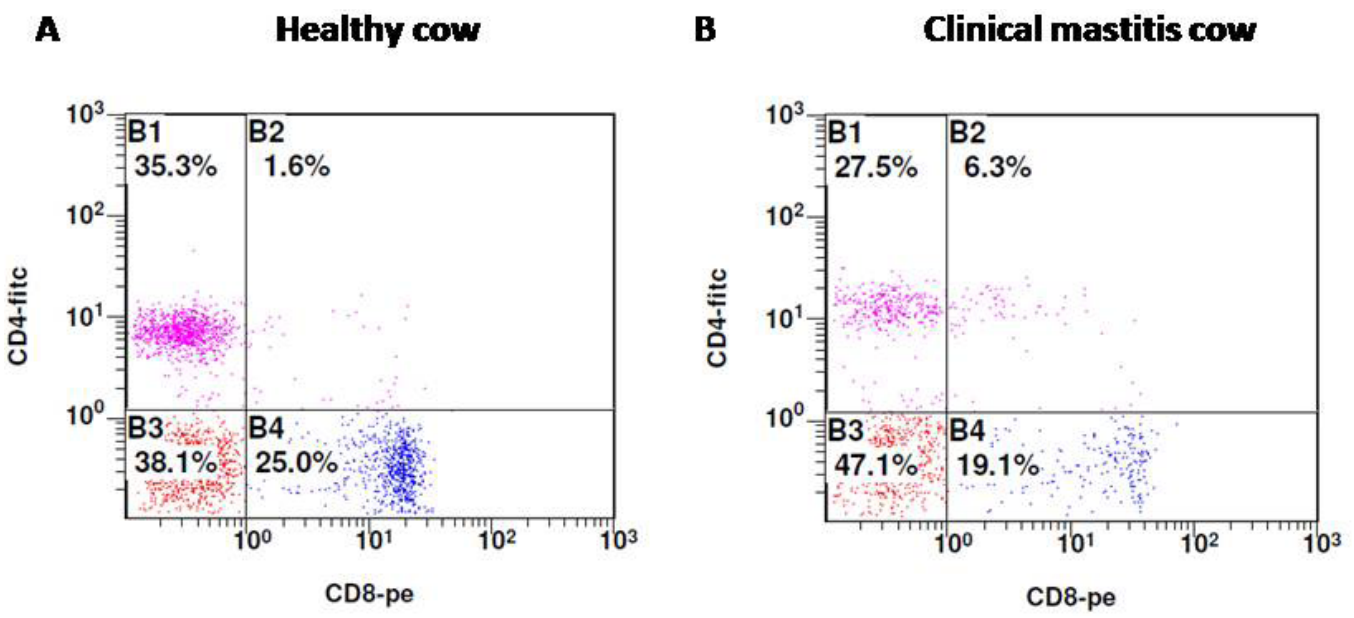

Figure 4. Flow cytometry analysis results of $\mathrm{CD}^{+} \mathrm{T}$ lymphocytes in peripheral blood of the healthy controls $(\mathrm{A})$ and the clinical mastitis cows $(\mathbf{B})$.

In humans, over $10 \%$ of common SNPs overlap with the differentially methylated region (DMR) between different alleles (Bell et al., 2010). DNA methylation changes can be influenced by genetic differences between animals. Nucleotide mutations in methylation regulator genes such as DNA methyltransferease (DNMTs), methylenetetrahydrofolate reductase (METHFR) or other genes may affect DNA methylation levels (El-Maarri et al., 2009; Feil and Fraga, 2012). To avoid the influence of different backgrounds of cows as far as possible, ANOVA was carried out to test the effects of different parities, SCC and mastitis status on DNA methylation level of the gene. Our results indicated that parity and SCC had no significant effects on the methylation level, while mastitis status was significantly associated with DNA methylation levels of $C D 4$ whether the cows were from different herds or from the same herd. Our previous in vivo study showed that Marek's disease virus may affect the DNA methylation stability of chicken CD4 gene (Luo et al., 2011). DNA methylation regulates alterations in gene expression that may lead to disease phenotypes, and underlie steady transgenerational alterations in phenotype (Jirtle and Skinner, 2007). However, other nonsignificant causes for the detected methylation level change of the CD4 region studied cannot be fully excluded, for example, I) natural occurring SNPs within regulators of DNA methylation between the animals (He et al., 2011) and II) the change in the relative portion of cell population in the whole blood samples induced by mastitis. Therefore, the results suggested that mastitis may cause high methylation level of bovine $C D 4$, and the causal relationship warrants a functional study.

In the current study, the $\mathrm{CpG}$ methylation levels of bovine $\mathrm{CD} 4$ promoter were checked by bisulfite pyrosequencing and validated by bisulfite cloning sequencing (BSP). For 
CpG methyaltion detection, BSP and bisulfite pyrosequencing assays are normally used (Reed et al., 2010; Liang et al., 2011). BSP has served as the "gold standard" for checking DNA methylation while pyrosequencing technology can rapidly detect methylation level without the traditional approach of cloning. BSP appears to be more sensitive than pyrosequencing at detecting hypermethylation of DNA and equal to pyrosequencing at detecting hypomethylation of DNA, while greater variability in the methylation of $\mathrm{CpG}$ sites was observed with BSP. It is possibly due to the cloning of bisulfite-treated DNA into bacterial expression vectors and sequencing 10 to 20 clones, whereas the ability of pyrosequencing is to reliably detect differences in DNA methylation across cell populations (Reed et al., 2010; Liang et al., 2011). This combination of the two methods is needed to detect hypermethylation of $\mathrm{CpG}$ sites.

In summary, dramatically upregulated promoter methylation of the CD4 gene in whole blood was identified in CM cows compared to healthy controls in Chinese Holsteins. The DNA methylation level of $C D 4$ was negatively correlated with $C D 4$ gene expression level in peripheral blood cells. On the basis of methylation pattern, the dendrogram using twodimensional hierarchical clustering analyses clearly distinguished the cows with $\mathrm{CM}$ from healthy cattle. These results implied that the DNA methylation status of bovine CD4 gene could be a promising epigenetic marker for selection against mastitis, which warrants the study of mastitis-contributing epigenetic mechanisms using $\mathrm{CD}^{+}$lymphocytes in dairy cattle.

\section{ACKNOWLEDGMENTS}

Research supported by the National Natural Science Foundation of China (\#31272420), the Fund for Basic Research from the Ministry of Education of the People's Republic of China (\#2011JS006), the Earmarked Fund for Modern Agro-industry Technology Research System (\#CARS-37-04B) and the National Science and Technology Project in Rural Areas (\#2011BAD28B02).

\section{REFERENCES}

Backdahl L, Bushell A and Beck S (2009). Inflammatory signalling as mediator of epigenetic modulation in tissue-specific chronic inflammation. Int. J. Biochem. Cell Biol. 41: 176-184.

Bell CG, Finer S, Lindgren CM, Wilson GA, et al. (2010). Integrated genetic and epigenetic analysis identifies haplotypespecific methylation in the FTO type 2 diabetes and obesity susceptibility locus. PLoS One 5: e14040.

Burton JL and Erskine RJ (2003). Immunity and mastitis. Some new ideas for an old disease. Vet. Clin. North. Am. Food Anim. Pract. 19: 1-45.

Choi JY, James SR, Link PA, McCann SE, et al. (2009). Association between global DNA hypomethylation in leukocytes and risk of breast cancer. Carcinogenesis 30: 1889-1897.

Chowdhury S, Erickson SW, MacLeod SL, Cleves MA, et al. (2011). Maternal genome-wide DNA methylation patterns and congenital heart defects. PLoS One 6: e16506.

de Haas Y, Barkema HW and Veerkamp RF (2002). The effect of pathogen-specific clinical mastitis on the lactation curve for somatic cell count. J. Dairy Sci. 85: 1314-1323.

El-Maarri O, Kareta MS, Mikeska T, Becker T, et al. (2009). A systematic search for DNA methyltransferase polymorphisms reveals a rare DNMT3L variant associated with subtelomeric hypomethylation. Hum. Mol. Genet. 18: 1755-1768.

Ellmeier W, Sawada S and Littman DR (1999). The regulation of CD4 and CD8 coreceptor gene expression during T cell development. Annu. Rev. Immunol. 17: 523-554.

Feil R and Fraga MF (2012). Epigenetics and the environment: emerging patterns and implications. Nat. Rev. Genet. 13: 97-109.

Fuchikami M, Morinobu S, Segawa M, Okamoto Y, et al. (2011). DNA methylation profiles of the brain-derived neurotrophic factor (BDNF) gene as a potent diagnostic biomarker in major depression. PLoS One 6: e23881.

Fujiwara Y, Chang AN, Williams AM and Orkin SH (2004). Functional overlap of GATA-1 and GATA-2 in primitive 
hematopoietic development. Blood 103: 583-585.

Halasa T, Nielen M, De Roos AP, Van HR, et al. (2009). Production loss due to new subclinical mastitis in Dutch dairy cows estimated with a test-day model. J. Dairy Sci. 92: 599-606.

He Y, Chu Q, Ma P, Wang Y, et al. (2011). Association of bovine CD4 and STAT5b single nucleotide polymorphisms with somatic cell scores and milk production traits in Chinese Holsteins. J. Dairy Res. 1-8.

Heinemeyer T, Wingender E, Reuter I, Hermjakob H, et al. (1998). Databases on transcriptional regulation: TRANSFAC, TRRD and COMPEL. Nucleic Acids Res. 26: 362-367.

Jirtle RL and Skinner MK (2007). Environmental epigenomics and disease susceptibility. Nat. Rev. Genet. 8: 253-262.

Landolfi MMT, Scollay R and Parnes JR (1997). Specific demethylation of the CD4 gene during CD4 T lymphocyte differentiation. Mol. Immunol. 34: 53-61.

Li W, Sun W, Liu L and Yang F (2010). IL-32: A host proinflammatory factor against influenza viral replication is upregulated by aberrant epigenetic modifications during influenza a virus infection. J. Immunol. 185: 5056-5065.

Liang B, Luo M, Scott-Herridge J, Semeniuk C, et al. (2011). A comparison of parallel pyrosequencing and sanger clonebased sequencing and its impact on the characterization of the genetic diversity of HIV-1. PLoS One 6: e26745.

Lin SY, Hsieh SC, Lin YC, Lee CN, et al. (2012). A whole genome methylation analysis of systemic lupus erythematosus: hypomethylation of the IL10 and IL1R2 promoters is associated with disease activity. Genes. Immun. 13: 214-220.

Luo J, Yu Y, Zhang H, Tian F, et al. (2011). Down-regulation of promoter methylation level of CD4 gene after MDV infection in MD-susceptible chicken line. BMC Proc. 5 (Suppl 4): S7.

Ma P, Yu Y, Zhang Y and Zhang Q (2010). The distribution of SCC and its correlation with milk production traits in Chinese Holsteins. Acta Vet. Zootechnica Sin. 41: 7.

Miglior F, Gong W, Wang Y, Kistemaker GJ, et al. (2009). Short communication: Genetic parameters of production traits in Chinese Holsteins using a random regression test-day model. J. Dairy Sci. 92: 4697-4706.

Nadeau K, McDonald-Hyman C, Noth EM, Pratt B, et al. (2010). Ambient air pollution impairs regulatory T-cell function in asthma. J. Allergy Clin. Immunol. 126: 845-852.

NMC (2011). National Mastitis Council 50th Annual Meeting. Current Status and Future Challenges in Mastitis Research. Available at [http://www.nmconling.org/meetings.html] or at [http://www.nmconline.org/articles/MastitisStatus. pdf]. Accessed July 22, 2011.

Reed K, Poulin ML, Yan L and Parissenti AM (2010). Comparison of bisulfite sequencing PCR with pyrosequencing for measuring differences in DNA methylation. Anal. Biochem. 397: 96-106.

Reinius LE, Acevedo N, Joerink M, Pershagen G, et al. (2012). Differential DNA methylation in purified human blood cells: implications for cell lineage and studies on disease susceptibility. PLoS One 7: e41361.

Rivas AL, Quimby FW, Blue J and Coksaygan O (2001). Longitudinal evaluation of bovine mammary gland health status by somatic cell counting, flow cytometry, and cytology. J. Vet. Diagn. Invest. 13: 399-407.

Rivas AL, Schwager SJ, Gonzalez RN, Quimby FW, et al. (2007). Multifactorial relationships between intramammary invasion by Staphylococcus aureus and bovine leukocyte markers. Can. J. Vet. Res. 71: 135-144.

Toperoff G, Aran D, Kark JD, Rosenberg M, et al. (2011). Genome-wide survey reveals predisposing diabetes type 2-related DNA methylation variations in human peripheral blood. Hum. Mol. Genet. 21: 371-383.

Vanselow J, Yang W, Herrmann J, Zerbe H, et al. (2006). DNA-remethylation around a STAT5-binding enhancer in the alphaS1-casein promoter is associated with abrupt shutdown of alphaS1-casein synthesis during acute mastitis. $J$. Mol. Endocrinol. 37: 463-477.

Wang Y, Chen L, Hagiwara N and Knowlton AA (2010). Regulation of heat shock protein 60 and 72 expression in the failing heart. J. Mol. Cell Cardiol. 48: 360-366.

Weber M, Hellmann I, Stadler MB, Ramos L, et al. (2007). Distribution, silencing potential and evolutionary impact of promoter DNA methylation in the human genome. Nat. Genet. 39: 457-466.

Wei G, Wei L, Zhu J, Zang C, et al. (2009). Global mapping of H3K4me3 and H3K27me3 reveals specificity and plasticity in lineage fate determination of differentiating CD4+ T cells. Immunity 30: 155-167.

Widschwendter M, Apostolidou S, Raum E, Rothenbacher D, et al. (2008). Epigenotyping in peripheral blood cell DNA and breast cancer risk: a proof of principle study. PLoS One 3: e2656.

Wilson AG (2008). Epigenetic regulation of gene expression in the inflammatory response and relevance to common diseases. J. Periodontol. 79: 1514-1519.

Yu Y, Zhang H, Tian F, Bacon L, et al. (2008a). Quantitative evaluation of DNA methylation patterns for ALVE and TVB genes in a neoplastic disease susceptible and resistant chicken model. PLoS One 3: e1731.

Yu Y, Zhang H, Tian F, Zhang W, et al. (2008b). An integrated epigenetic and genetic analysis of DNA methyltransferase genes (DNMTs) in tumor resistant and susceptible chicken lines. PLoS One 3: e2672.

Zhou G (2007). Immunology Theory. Shanghai Science and Technology. Publishing House. P.R., China.

Zou YR, Sunshine MJ, Taniuchi I, Hatam F, et al. (2001). Epigenetic silencing of CD4 in T cells committed to the cytotoxic lineage. Nat. Genet. 29: 332-336. 